\title{
Reliability and validity of the Persian (Farsi) version of the Risk Perception Survey-Diabetes Mellitus
}

\author{
S. Soltanipour, ${ }^{7}$ A. Heidarzadeh ${ }^{7}$ and A. Jafarinezhad ${ }^{2}$
}

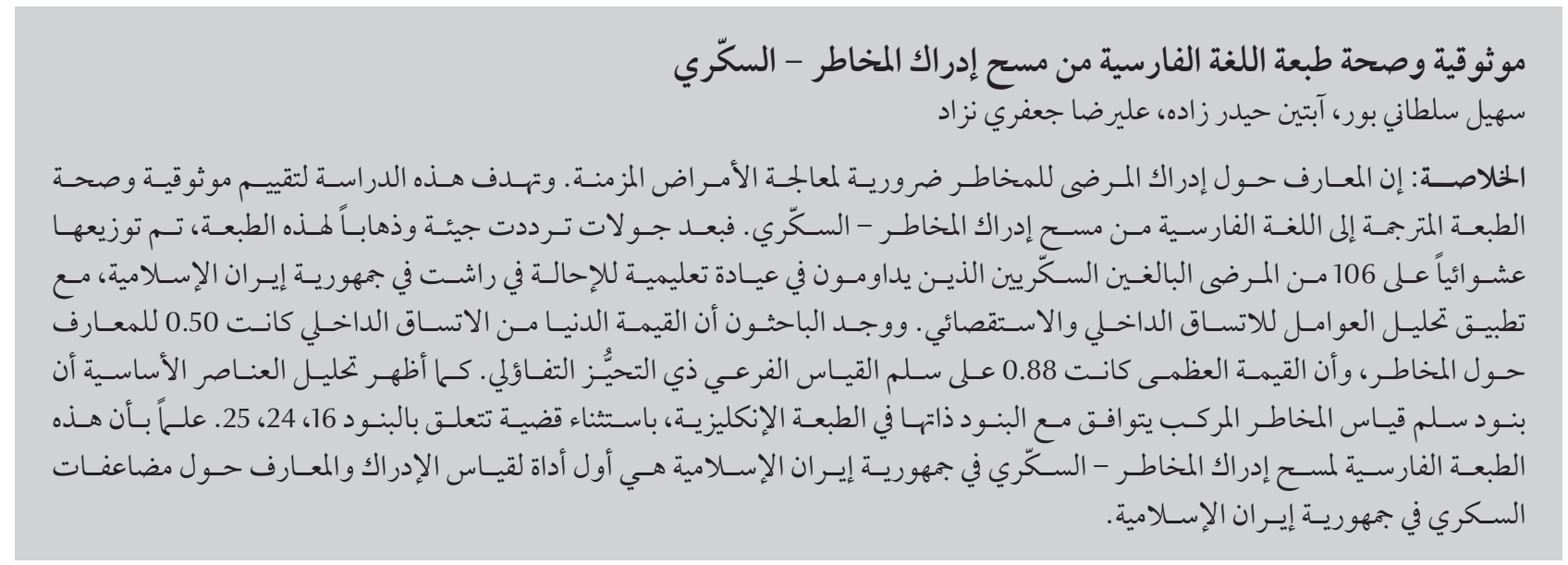

ABSTRACT Knowledge of patients' risk perceptions is essential for the management of chronic diseases. This study aimed to assess the reliability and validity of a Persian (Farsi) language translation of the Risk Perception Survey-Diabetes Mellitus. After forward-backward translation the RPS-DM was randomly administered to 106 adult patients with diabetes who were enrolled in a teaching referral clinic in the north of the Islamic Republic of Iran (Rasht). Internal consistency and exploratory factor analysis were applied. The minimum value for internal consistency was 0.50 for risk knowledge and the highest value was 0.88 on the optimistic bias subscale. Principal component analysis showed that the items of the composite risk score matched with the same items in the English language version, except for question numbers 16, 24 and 25. The Persian version of RPS-DM is the first standardized tool for measuring risk perception and knowledge about diabetes complications in the Islamic Republic of Iran.

Fiabilité et validité de la version en langue perse (farsi) de l'enquête sur la perception du risque pour le diabète

RÉSUMÉ La connaissance de la perception du risque par les patients est essentielle pour la prise en charge des maladies chroniques. La présente étude visait à évaluer la fiabilité et la validité de la version en langue perse (farsi) de l'enquête sur la perception du risque pour le diabète. Après traduction puis rétro-traduction, l'enquête menée a été réalisée aléatoirement auprès de 106 patients adultes atteints de diabète qui avaient été recrutés dans un établissement de soins universitaire spécialisé dans le nord de la République islamique d'Iran (Rasht). La cohérence interne et l'analyse factorielle exploratoire ont été appliquées. La valeur minimale pour la cohérence interne était de 0,50 pour les connaissances du risque et la valeur maximale était de 0,88 sur la sous-échelle du biais d'optimisme. L'analyse des composantes principales a révélé que les items du score du risque composite correspondaient aux mêmes items dans la version en langue anglaise, à l'exception des questions 16, 24 et 25. La version en langue perse de l'enquête est le premier instrument de mesure normalisé de la perception du risque et des connaissances sur les complications du diabète en République islamique d'Iran.

${ }^{7}$ Department of Community Medicine; ${ }^{2}$ Department of Internal Medicine, Guilan University of Medical Science, School of Medicine, Rasht, Islamic Republic of Iran (Correspondence to S. Soltanipour: ssoltanipour@yahoo.com).

Received: 10/02/13; accepted: 23/06/13 


\section{Introduction}

Diabetes, through its complications, is responsible for a growing burden of disease and is the major cause of premature death [1]. The risk of diabetes is growing among all socioeconomic classes of the population, and the International Diabetes Federation estimates that the greatest burden of diabetes is in countries of the Middle East [2]. The prevalence of diabetes is rising in the Islamic Republic of Iran [3]. Moreover, in a survey of the level of care for patients with diabetes in the Iranian diabetes control and prevention programme all measures of process and outcome except eye examination were rated as weak. Better self-care training programmes for people with diabetes have been recommended [4].

Knowledge of people's risk perceptions is essential for the management of any disease risk prevention programme $[5,6]$; health practitioners need to know what patients think and how they respond to the hazards threatening their well-being. Lack of such information usually hinders the development of disease prevention programmes [7]. Patients' self-care and awareness of unfavourable health events are the major elements of chronic disease prevention and care, especially for people with diabetes [8]. There are a few reports about diabetes risk perception [9-11]. There is evidence for a positive correlation between people's risk perception and their recognition of the negative consequences, symptoms and negative emotions associated with diabetes [9], as well as their willingness to engage in diabetes prevention activities [12]. A significant negative relationship between general well-being and perception of risk for diabetes complications has been noted [9].

The low level of research of this issue in the Islamic Republic of Iran can be linked to the lack of a Persian (Farsi) language instrument for studying diabetes risk perception. The Risk Perception
Survey-Diabetes Mellitus (RPS-DM) is a 31-item survey for people with diagnosed diabetes (type 1 or 2 ) to assess comparative risk perceptions related to diabetes and its complications, including an environmental risk subscale [13]. The English language RPS-DM with English scoring instructions was the only multidimensional questionnaire existing for this purpose. Therefore, we decided to assess the reliability and validity of the Persian translation of the RPS-DM.

\section{Methods}

\section{Study tool}

The RPS-DM was originally developed for patients with a diagnosis of diabetes who were older than 18 years of age, receiving diabetes care and able to read and speak English or Spanish and was tested among the residents of the Bronx, New York. The psychometric properties of the original questionnaire and the process of its development has been cited elsewhere [10]. A version of the PRS-DM and its scoring can be downloaded from the Internet [13].

The RPS-DM consists of 31 questions. The first section assesses risk knowledge (5 items scored on 3-point scale with 1 point for each correct answer; higher score indicates greater knowledge of the risk of getting diabetes complications). The remaining 26 items comprise 5 subscales which can be described as: perceived personal control (4 items scored on 4-point scale; higher average score on subscale indicates more perceived control and less perceived risk of disease); worry (2 items scored on 4-point scale; higher average score on subscale indicates more worry about getting problems), optimistic bias (2 items scored on 4-point scale; higher average score on subscale indicates more optimistic bias and lower score indicates more realism/pessimism about getting complications); personal disease risk (9 items scored on a 4-point scale; indicates degree of own perceived risk of getting 9 diseases or conditions, plus additional question about whether they have ever had the condition, scored yes/no with 1 point added for yes response; higher average score on subscale indicates greater perceived personal disease risk); and environmental risk (9 items scored on a 4-point scale; higher average score on subscale indicates greater perceived risk of 9 potential hazards in the environment). The composite risk perception is the average of the 26 items in the main questionnaire; higher scores indicate greater comparative perceived risk [10].

\section{Persian language version}

For the current study the original questionnaire was translated into Persian language and tested by the backwardforward translation method after the permission of its creator. Two highly experienced diabetes experts reviewed the final Persian version of the questionnaire and qualitatively confirmed its content and face validity.

\section{Sample and data collection}

After obtaining permission from the research council of Guilan University of Medical Science, patients who could understand and speak Persian without any problems influencing their interpretive analysis were recruited for the study. Between 22 December 2011 to 19 March 2012 patients registered in a referral special diabetes clinic in Rasht in the north of the Islamic Republic of Iran were randomly selected by computer from the waiting list of scheduled visits. The study was explained to the patients and an oral informed consent for participation was obtained. The RPS-DM Persian version questionnaire was delivered through face-to-face interviews by trained staff. A total of 106 people with diabetes completed the interviews.

\section{Data analysis}

Discrimination and difficulty indices measuring knowledge about diabetes 
complications were calculated. Cronbach alpha and the Kuder-Richardson formula 20 was adopted for assessing the internal consistency and the Spearman correlation coefficient was calculated between item scores and total scores of each subscale to evaluate the construct validity. Exploratory factor analysis was used to check the construct validity of the composite risk perception. The statistical examination of the data was performed using SPSS, version 16.0.2 program.

\section{Results}

The survey was administered to 119 adult patients with diabetes and 106 completed the interviews, a response rate of $89 \%$. There were no significant demographic differences detected between respondents and nonrespondents. Selected characteristics of the study participants are shown in Table 1. A majority were women (65.1\%). The median period since the diagnosis of diabetes was 10 years, with a minimum and maximum of 1 to 40 years.
For the risk knowledge items the discrimination index was $0.70,0.70$, $0.55,0.77$ and 0.74 for item numbers 1 to 5 respectively and the difficulty indices were $0.64,0.64,0.72,0.61$ and 0.62 respectively.

After correcting the item scores, coefficients of Kuder-Richardson-20 and Cronbach alpha for reliability were calculated (Table 2). The minimum value for internal consistency was 0.50 for risk knowledge and the highest value was 0.88 on the optimistic bias subscale. There was a significant linear correlation between the total score and scores for questions in each subscale. The minimum Spearman correlation coefficient was 0.44 for item numbers 24,25 and the maximum was 0.95 for item number 9 (Table 3). At first, the 26 items that made up the composite risk perception score were examined for factorability. All items correlated at 0.5 with at least 1 other item. The Kaiser-Meyer-Olkin measure of sampling adequacy was 0.71 $(P<0.001)$ and the Bartlett test of sphericity was significant $\left(\chi_{325}^{2}=1203.8\right.$, $P<0.001)$. The diagonal of the antiimage correlation matrix was 0.5 . All the communalities were calculated to be above 0.4 .

We used principal component analysis because the purpose was to show and calculate items of the composite risk perception score. Early analysis with eigenvalues 1.0 revealed that the 1st, 2nd, 3rd and 4th factors explained $21 \%, 13 \%, 9 \%$ and $7 \%$ of the variance respectively. The 5 th and 6 th factors both explained $5 \%$ of the variance and the 7 th factor explained $4 \%$ of the variance. The authors preferred 5-factor varimax rotation (which explained $56.5 \%$ of the variance) because the original composite risk perception score was composed of 5 subscales. Items loaded 0.4 and above were selected. Matrices of rotated factors showed that items included in the composite risk score matched with the original English-language version, except for item numbers 24 and 25 , which could not be classified with the other items on the environmental risk subscale, and item 16, which appeared on the worry subscale instead of the personal risk subscale (Table 4). Personal disease risk item number 14 and environmental risks items 23 and 26

\begin{tabular}{|c|c|c|}
\hline Characteristic & $\begin{array}{c}\text { Males } \\
(n=37)\end{array}$ & $\begin{array}{l}\text { Females } \\
(n=69)\end{array}$ \\
\hline Age [mean (SD) years] & $57.1(13.1)$ & $54.5(10.5)$ \\
\hline \multirow[t]{2}{*}{ Time from diagnosis of diabetes [median (min.-max.) years] } & $7(1-27)$ & $10(1-40)$ \\
\hline & $\%$ & $\%$ \\
\hline \multicolumn{3}{|l|}{ Body mass index $\left(\mathrm{kg} / \mathrm{m}^{2}\right)$} \\
\hline$<18.5$ & 2.7 & 4.3 \\
\hline $18.5-<25$ & 48.6 & 36.2 \\
\hline $25-<30$ & 37.8 & 40.6 \\
\hline$\geq 30$ & 10.8 & 18.8 \\
\hline \multicolumn{3}{|l|}{ Education level } \\
\hline Illiterate & 21.6 & 50.7 \\
\hline Below diploma & 40.5 & 29.0 \\
\hline Diploma & 27.0 & 15.9 \\
\hline University & 10.8 & 43.0 \\
\hline \multicolumn{3}{|l|}{ Diabetes adverse events } \\
\hline Yes & 62.2 & 63.8 \\
\hline No & 37.8 & 36.2 \\
\hline
\end{tabular}

$S D=$ standard deviation; min. = minimum; $\max .=$ maximum . 


$\begin{aligned} & \text { Table } 2 \text { Internal consistency of the risk knowledge and the risk perception subscales } \\
& \text { of the Persian (Farsi) version of the Risk Perception Survey-Diabetes Mellitus }\end{aligned}$
\begin{tabular}{lcc}
\hline Subscale description & Total no. of items & Reliability coefficient $(r)$ \\
\hline Risk knowledge & 5 & $0.50^{\mathrm{a}}$ \\
Perceived personal control & 4 & $0.73^{\mathrm{b}}$ \\
Worry & 2 & $0.82^{\mathrm{b}}$ \\
Optimistic bias & 2 & $0.88^{\mathrm{b}}$ \\
Personal disease risk & 9 & $0.87^{\mathrm{b}}$ \\
Environmental risk & 9 & $0.78^{\mathrm{b}}$ \\
Composite risk perception & 26 & $0.79^{\mathrm{b}}$ \\
\hline
\end{tabular}

${ }^{a}$ Kuder-Richardson formula 20; ${ }^{b}$ Cronbach apha.

Table 3 Correlation between each subscale score and the items included in the Persian (Farsi) version of the Risk Perception Survey-Diabetes Mellitus

\begin{tabular}{|c|c|}
\hline Subscale description/Item no. & Correlation coefficient ${ }^{\mathrm{c}}(\boldsymbol{r})$ \\
\hline \multicolumn{2}{|l|}{ Risk knowledge } \\
\hline 1 & 0.51 \\
\hline 2 & 0.62 \\
\hline 3 & 0.58 \\
\hline 4 & 0.65 \\
\hline 5 & 0.62 \\
\hline \multicolumn{2}{|l|}{ Perceived personal control } \\
\hline 6 & 0.70 \\
\hline 7 & 0.81 \\
\hline $11^{\mathrm{a}}$ & 0.53 \\
\hline $13^{\mathrm{a}}$ & 0.50 \\
\hline \multicolumn{2}{|l|}{ Worry } \\
\hline $8^{a}$ & 0.93 \\
\hline $12^{\mathrm{a}}$ & 0.90 \\
\hline \multicolumn{2}{|l|}{ Optimistic bias } \\
\hline $9^{a}$ & 0.95 \\
\hline $10^{\mathrm{a}}$ & 0.78 \\
\hline \multicolumn{2}{|l|}{ Personal disease risk ${ }^{b}$} \\
\hline 14 & 0.64 \\
\hline 15 & 0.75 \\
\hline 16 & 0.56 \\
\hline 17 & 0.50 \\
\hline 18 & 0.56 \\
\hline 19 & 0.62 \\
\hline 20 & 0.79 \\
\hline 21 & 0.77 \\
\hline 22 & 0.75 \\
\hline \multicolumn{2}{|l|}{ Environmental risk } \\
\hline 23 & 0.62 \\
\hline 24 & 0.44 \\
\hline 25 & 0.44 \\
\hline 26 & 0.57 \\
\hline 27 & 0.54 \\
\hline 28 & 0.58 \\
\hline 29 & 0.70 \\
\hline 30 & 0.66 \\
\hline 31 & 0.55 \\
\hline
\end{tabular}

${ }^{a}$ Reverse scored; ${ }^{b}$ Includes supplemental yes/no questions about ever having problem. ${ }^{c}$ All were significant at $P<0.001$. additionally grouped with the worry subscale items.

\section{Discussion}

Except for risk knowledge, all the other 5 subscales of the RPS-DM were judged to have fair reliability in the current study [14]. Difficulty and discrimination analysis showed that items evaluating the risk knowledge of participants had desirable levels of difficulty and discrimination [14]. With the exception of the worry and optimistic bias subscales, which have very strong and strong construct validity respectively, all the other subscales included in the questionnaire had Spearman correlad tion coefficients indicating moderate to strong construct validity. Exploratory factor analysis showed that all items in the composite risk perception (with the exception of item numbers 16,24 and 25) fitted with the subscales of the original questionnaire.

Little evidence exists about the risk perceptions of people with diabetes. Walker et al. applied the RPS-DM and concluded that the questions evaluating knowledge among a sample of patients from New York did not show respectable reliability, especially when using the Spanish version with Spanish speakers. The personal control and worry subscales have less reliability than other subscales, as in Walker et al.'s study [10]. We showed similar results for the knowledge subscale; however, the other subscales in the Persian version of the questionnaire displayed high reliability. We believe that our cases selected from a teaching referral clinic could better assess the reliability of the Persian questionnaire, as in Kim et al.'s study, which surveyed women who enrolled in a managed care plan at an academic medical centre [15].

The research evidence has revealed that risk perception is closely related to the experiences of individuals in their geographical and climatic environment 


\begin{tabular}{|c|c|c|c|c|c|c|}
\hline \multirow{3}{*}{$\begin{array}{l}\text { Item } \\
\text { no. }\end{array}$} & \multirow{3}{*}{ Item } & \multicolumn{5}{|c|}{ Factors } \\
\hline & & 1 & 2 & 3 & 4 & 5 \\
\hline & & $\begin{array}{l}\text { Personal } \\
\text { disease risk }\end{array}$ & $\begin{array}{l}\text { Environmental } \\
\text { risk }\end{array}$ & Worry & $\begin{array}{l}\text { Optimistic } \\
\text { bias }\end{array}$ & $\begin{array}{c}\text { Perceived } \\
\text { personal } \\
\text { control }\end{array}$ \\
\hline & $\begin{array}{l}\text { The statements below are about your risk (or } \\
\text { chances) of having diabetes health problems }\end{array}$ & & & & & \\
\hline 6 & $\begin{array}{l}\text { I feel that I have little control over risks to my } \\
\text { health }^{\mathrm{a}}\end{array}$ & - & - & - & - & 0.60 \\
\hline 7 & $\begin{array}{l}\text { If I am going to get complications from diabetes, } \\
\text { there is not much I can do about it }{ }^{\mathrm{a}}\end{array}$ & - & - & - & - & 0.73 \\
\hline 11. & $\begin{array}{l}\text { My own efforts can help control my risks of } \\
\text { getting diabetes complications }\end{array}$ & - & - & - & - & 0.59 \\
\hline 13 & $\begin{array}{l}\text { If I make a good effort to control the risks of } \\
\text { diabetes complications, I am much less likely to } \\
\text { get complications }\end{array}$ & - & - & - & - & 0.59 \\
\hline 8 & $\begin{array}{l}\text { I am very concerned about getting diabetes } \\
\text { health problems }\end{array}$ & - & - & 0.75 & - & - \\
\hline 12 & I worry about getting diabetes complications $\mathrm{s}^{\mathrm{a}}$ & - & - & 0.74 & - & - \\
\hline 9 & $\begin{array}{l}\text { Compared to other people with diabetes of my } \\
\text { same age and sex, I am less likely than they are } \\
\text { to get diabetes complications }\end{array}$ & - & - & - & 0.90 & - \\
\hline 10 & $\begin{array}{l}\text { Compared to other people with diabetes of my } \\
\text { same age and sex, I am less likely to have serious } \\
\text { health problems }\end{array}$ & - & - & - & 0.90 & - \\
\hline & Below is a list of health problems and diseases & & & & & \\
\hline 14 & Heart attack & 0.44 & - & 0.51 & - & - \\
\hline 15 & Foot amputation & 0.75 & - & - & - & - \\
\hline 16 & Cancer & - & - & 0.48 & - & - \\
\hline 17 & Vision problems & 0.76 & - & - & - & - \\
\hline 18 & High blood pressure & 0.69 & - & - & - & - \\
\hline 19 & Numb feet & 0.70 & - & - & - & - \\
\hline 20 & Stroke & 0.65 & - & - & - & - \\
\hline 21 & Blindness & 0.79 & - & - & - & - \\
\hline 22 & Kidney failure & 0.74 & - & - & - & - \\
\hline & $\begin{array}{l}\text { The following is a list of possible hazards or } \\
\text { dangerous conditions in the environment } \\
\text { around most of us }\end{array}$ & & & & & \\
\hline 23 & Medical tests (e.g. X-ray, MRI) & - & 0.54 & 0.48 & - & - \\
\hline 24 & Violent crime & - & - & - & - & - \\
\hline 25 & Extreme weather (hot or cold) & - & - & - & - & - \\
\hline 26 & Driving/riding in an automobile (car) & - & 0.40 & 0.53 & - & - \\
\hline 27 & Street drugs (illegal drugs) & - & 0.56 & - & - & - \\
\hline 28 & Air pollution & - & 0.59 & - & - & - \\
\hline 29 & Pesticides & - & 0.77 & - & - & - \\
\hline 30 & Household chemicals (cleaners) & - & 0.76 & - & - & - \\
\hline 31 & $\begin{array}{l}\text { Cigarette smoke from people smoking around } \\
\text { you }\end{array}$ & - & 0.75 & - & - & - \\
\hline
\end{tabular}

${ }^{a}$ Reverse scored.

$M R I=$ magnetic resonance imaging . 
[5]. Participants in our study were living in a region with a temperate climate [16] and low crime rates $[17,18]$. So it was not surprising that item numbers 24 and 25 (which measure respondents' concerns about risk from violent crime and extreme hot/cold weather respectively) could not be classified with the other items on the environmental risk subscale.

Despite the evidence supporting diabetes as a risk factor for cancers [19], it seemed there was a lack of knowledge among our sample about an association between diabetes and cancer. Factor analysis revealed that question number 16 (about risk of cancer) could not be classified among the items seeking to measure personal risk; however, the other questions of the personal risk subscale could be classified together. In the Iranian programme of diabetes control and prevention there is considerable educational information about the complications of diabetes, except for the relationship between cancer and diabetes. Nevertheless, it seems that our patients knew little about this aspect of diabetes, and when they were asked about their personal risk of cancer in addition the complications known to them, this caused misclassification of question number 16 on the worry subscale not the personal risk subscale. Meanwhile, item number 14 (risk of heart attack) was expected to be categorized only as a personal disease risk and items 23 (risk from medical tests such as X-rays, MRI) and 26 (risk from driving/ riding in an automobile) were expected to group only with environmental risks. However, perhaps because these are prevalent, comprehensible and alarming issues in the Islamic Republic of Iran [20], they additionally grouped with the worry subscale items numbers 8 and 12 in the factor analyses.

In summary, the RPS-DM questionnaire was translated for the first time into the Persian language and its reliability and validity was surveyed in a sample of patients who were enrolled in an academic referral clinic. Thus, the results can be generalized to larger groups only with caution. This questionnaire combined the scores of the several subscales and obtained a measure of risk perception and knowledge about diabetes complications by quantitative methods. Doctors, nurses and other health care professionals can use this questionnaire for better communication and understanding about self-care among Iranian patients with diabetes. As social, cultural and environmental causes influence risk perception, we emphasize the need for using a native language instrument for more clarity of evidence.

\section{Acknowledgements}

The authors wish to thank Dr E.A. Walker for permitting us to use the questionnaire. The authors also thank Dr M. Sadeghi for his invaluable help.

Funding: None.

Competing interests: None declared.

\section{References}

1. Javanbakht $M$ et al. Health related quality of life in patients with type 2 diabetes mellitus in Iran: a national survey. PLOS ONE, 2012, 7:e44526.

2. Javanbakht $M$ et al. Cost-of-illness analysis of type 2 diabetes mellitus in Iran. PLOS ONE, 2011, 6:e26864.

3. Wild $\mathrm{S}$ et al. Global prevalence of diabetes: estimates for the year 2000 and projections for 2030. Diabetes Care, 2004, 27:1047-1053.

4. Delavari A et al. Quality of care of diabetes mellitus type II patients in Iran. Archives of Iranian Medicine, 2009, 12:492-495.

5. The world health report 2002: reducing risk promoting healthy life. Geneva, World Health Organization, 2002.

6. Hivert MF et al. Diabetes risk perception and intention to adopt healthy lifestyles among primary care patients. Diabetes Care, 2009, 32:1820-1822.

7. Slovic P. Perception of risk. Science, 1987, 236:280-285.

8. Walker EA et al. Risk perception for developing diabetes: comparative risk judgments of physicians. Diabetes Care, 2003, 26:2543-2548.

9. Calvin D et al. African Americans' perception of risk for diabetes complications. Diabetes Educator, 2011, 37:689-698.

10. Walker EA et al. Measuring comparative risk perceptions in an urban minority population: the risk perception survey for diabetes. Diabetes Educator, 2007, 33:103-110.

11. Adriaanse MC et al. Perceived risk for Type 2 diabetes in participants in a stepwise population-screening programme. Diabetes Medicine, 2003, 20(3):210-215.

12. Pinelli NR et al. Perceived risk and the willingness to enroll in a diabetes prevention lifestyle intervention in Arab-Americans. Diabetes Research and Clinical Practice, 2010, 90:e27-e29.
13. Risk Perception Survey-Diabetes Mellitus (RPS-DM) and scoring guide. English version [Internet] (http://www.einstein.yu.edu/ docs/centers/diabetes-research/rpsdm_print_eng.pdf, accessed 24 November 2013).

14. Understanding item analysis reports. Seattle, Washington, Office of Educational Assessment [Internet] (http://www. washington.edu/oea/services/scanning_scoring/scoring/ item_analysis.html, accessed 30 December 2013).

15. Kim C et al. Risk perception for diabetes among women with histories of gestational diabetes mellitus. Diabetes Care, 2007, 30:2281-2286.

16. Rasht climate guide. Iran. World climate guide [Internet] (http://www.worldclimateguide.co.uk/climateguides/iran/ rasht.php. accessed 24 November 2013).

17. Intentional homicide, count and rate per 100,000 population (1995-2017). United Nations Office on Drugs and Crime [Internet] (http://www.unodc.org/documents/data-and-analysis/ statistics/crime/Homicide_statistics2012.xls, accessed 24 November 2013).

18. Theft at the national level, number of police-recorded offences. United Nations Office on Drugs and Crime [Internet] (http:// www.unodc.org/documents/data-and-analysis/statistics/ crime/CTS12_Theft.xls, accessed 24 November 2013).

19. Zhang $\mathrm{PH}$ et al. Increased risk of cancer in patients with type 2 diabetes mellitus: a retrospective cohort study in China. BMC Public Health, 2012, 12:567.

20. Naghavi M et al. The burden of disease and injury in Iran 2003. Population Health Metrics, 2009, 7:9. 